\title{
Number Sense in Siblings of Children with Mathematical Learning Disabilities: A Longitudinal Study
}

\author{
Magda Praet, Daisy Titeca, Annelies Ceulemans and Annemie Desoete*
}

\author{
Annemie Desoete, Department of Experimental Clinical and Health Psychology, Developmental Disorders, \\ Henri Dunantlaan 2, 9000 Ghent, Belgium
}

\begin{abstract}
Number sense, counting and logical thinking were assessed in 14 siblings of children with Mathematical Learning Disabilities (MLD) and in 41 age matched children without family members with MLD. The children were tested in kindergarten and followed up in grade 1. A 0-100 number line estimation paradigm with three formats (Arabic digits, dots and number) was used as a measure of number sense. Results reveal that siblings of children with MLD are less proficient in number line placements compared to non-siblings, with both groups having a logarithmic representation in kindergarten and grade 1 . Siblings also differ from non siblings on procedural and conceptual counting knowledge and logical thinking in kindergarten. In addition, our findings suggest that nnumber line estimation in kindergarten is especially predictive for untimed procedural calculation performances in grade 1, whereas procedural counting knowledge is related to timed fact retrieval skills in grade 1. Our findings also reveal that MLD had a familial aggregation. Clinical siblings especially differ from non-clinical siblings on the estimation with Arabic numbers (in kindergarten and grade 1) and number words (in grade 1), pointing to the fact that especially symbolic number line estimation tasks on a 0-100 scale can be used as screeners for MLD. Implications for the understanding and diagnosis of MLD are discussed.
\end{abstract}

Keywords: Mathematical learning disabilities, number sense, siblings, number line estimation, Arabic numbers, number words, counting, logical thinking, arithmetic.

\section{INTRODUCTION}

Mathematical learning disabilities (MLD) refer to a significant degree of impairment in arithmetic skills. The child's level of attainment is substantially below that expected for a child of the same age. and remediation or extra instruction does not lead to the catching up on peers. In addition, the below average performances can not be totally explained by impairments in general intelligence or by external factors that could provide sufficient evidence for scholastic failure. Most practitioners and researchers currently report a prevalence of MLD between $2-14 \%$ of children [1]. The prevalence of MLD in siblings even ranges from 40 to $64 \%$ [2].

There are several models trying to explain MLD $[3,4]$. There has been research on counting in predicting the diagnosis of MLD [5]. Dowker [6] added that counting performances depend on procedural and conceptual knowledge. Procedural knowledge refers to children's ability to perform a counting task, for example, a child succeeds determining that there are five objects in an array. Conceptual counting knowledge reflects a child's understanding of the counting principles: the stable order principle, the oneone-correspondence principle and the cardinality

\footnotetext{
*Address correspondence to this author at the Annemie Desoete, Department of Experimental Clinical and Health Psychology, Developmental Disorders, Henri Dunantlaan 2, 9000 Ghent, Belgium; Tel: +32.9.2648626; Fax: +32 9264 64 89; E-mail: Annemie.Desoete@Ugent.be
}

principle. In addition to counting, the value of including logical thinking abilities $[7,8]$ to diagnose MLD has been stressed.

Recently several studies focus on 'number sense' a term denoting the ability to picture and manipulate numerical magnitude on an internal number line $[3,9,10]$, because there is behavioral evidence of a more imprecise or deficient magnitude representation in children with MLD [10-12]. In addition MLD participants showed both structural and functional differences in this brain regions involved in the processing of magnitudes [13-16]. A Number Line Estimation (NLE) paradigm has been used as a measure of number sense $[17,18]$. In line with the triple-code model, numbers can be represented as a visual Arabic code, an auditory verbal code, and an analog magnitude code [19]. As a result, it is useful to include three formats (Arabic digits, dots and number) in the NLE task.

\section{Objectives}

This a follow up to Shalev et al. and Desoete et al. determining the familial aggregation of $\operatorname{MLD}[2,20]$. The study expands the previous studies by using a longitudinal design. We examine number sense, counting knowledge and logical thinking in the screening of MLD. We expect below-average performances in siblings but not in children without family members with MLD. In addition, we will compare the skills of siblings developing MLD themselves and 
sibling not developing MLD. Finally the relationship between number sense and counting in kindergarten and untimed procedural calculation and timed fact retrieval skills in grade 1 will be studied.

\section{METHOD}

\section{Participants}

Participants were 14 siblings ( 7 girls) and 41 age matched peers (19 girls) without family members with MLD who entered the study in kindergarten (at the age of 67.83 months, $S D=4.45$ ) and were followed up in grade 1 (at the age of 82.76 months, $S D=4.02$ ). Children were classified as sibling if they had an older brother or sister (in grade 3 till 9) with a clinical diagnosis of MLD. Control children came from 3 school in Flanders. All parents accepted that this child was included in the study. All siblings and control peers were average intelligent. $(M=101.76, S D=13.56)$. There was no significant difference between children with and without siblings with MLD on age $(F(1,53)=1.027$, $\left.p=.315, \eta^{2}=.02\right)$ or intelligence $(F(1,53)=1.096, p=.300$, $\left.\eta^{2}=.02\right)$.

\section{Instruments}

In order to have an estimation of the intellectual capacities of the children they underwent an assessment of intelligence with the WPPSI-III-NL in kindergarten [21].

Number sense was assessed in kindergarten (T1) and in grade 1 (T2) with a number-line estimation (NLE) paradigm. In line with previous research an 0100 interval was used $[17,18]$.The NLE task included three exercise trials and 27 test trials with 9 trials for each code. In the visual Arabic condition, stimuli were presented as Arabic numerals. In the auditory verbal condition, stimuli were presented as spoken number words, and in the analog magnitude condition, stimuli were presented as dot patterns. The dot patterns were controlled for perceptual variables using the procedure of Dehaene and colleagues [19,22], meaning that on half of the trials dot size was held constant, and on the other half, the size of the total occupied area of the dots was held constant. Children were asked to put a single mark on the line to indicate the location of the number. No feedback was given to participants regarding the accuracy of their marks. The percentage absolute error (PAE) was calculated per child as a measure of children's estimation accuracy following the formula of Siegler and Booth [23]. If a child was asked to estimate 25 on a $0-100$ number line and placed the mark at the point on the line corresponding to 40 , the PAE would be (40-25) / 100 or $15 \%$. In addition, the estimation distribution was studied with a regression analyses to investigated if children had a logarithmic or linear representation of numbers.

Procedural and conceptual counting knowledge and logical abilities were tested with different subtests of the TEDI-MATH [24] in kindergarten (T1). In the subtest procedural counting of the TEDI-MATH children had to count forward to an upper bound (e.g., 'count up to 6'), count forward from a lower bound (e.g., 'count from 3') and count forward with an upper and lower bound (e.g., 'count form 5 up to 9') is assessed. One point was given for a correct answer. The internal consistency of this task is good, with Cronbach's alpha $=.73[24]$. In the subtest conceptual counting of the TEDI-MATH children had to judge the counting of linear and random patterns of drawings and counters. They were asked questions as 'How many objects are there in total?', or 'How many objects are there if you start counting with the leftmost object in the array?'. When children have to count again to answer, they do not gain any points, as this is considered to represent good procedural knowledge, but a lack of understanding of the counting principles. One point was given for a correct answer with a correct motivation (e.g., you did not add objects so the number of objects has not changed). The internal consistency of this task is good, with Cronbach's Alpha $=.85$ [24]. Logical abilities were assessed using seriation and classification tasks of the TEDI-MATH. Children had to seriate numbers (e.g., 'Sort the cards from the one with the fewest trees to the one with the most trees') and make groups of cards in order to assess the classification of numbers (e.g., 'Make groups with the cards that go together'). The internal consistency of this task is good with Cronbach's Alpha of .73 [24].

In grade 1 (T2) two arithmetic tests were used: The Revised Kortrijk Arithmetic Test (KRT-R) and the Arithmetic Number Facts Test (TTR). The KRT-R is an untimed standardized test on procedural calculations [25]. KRT-R requires that children solve calculations in a number-problem format (e.g., $16-12=\ldots$ ), and in a word-problem format (e.g., 1 less than 8 is ...). The psychometric value of the test has been demonstrated on a sample of 3,246 children. A validity coefficient (correlation with school results) and reliability coefficient (Cronbach's alpha) of .50 and .92 respectively were found for first grade [25]. The TTR is a 'timed' test consisting of 80 arithmetic number fact 
problems [26]. Children have to solve as many additions (e.g., $5+2=\ldots$ ) and subtractions (e.g., $6-5$ $=\ldots)$ in two minutes. The TTR is a standardized test that is frequently used in Flemish education as a measure of number-fact retrieval. The psychometric value of the test has been demonstrated on a sample of 10,059 children, revealing a Cronbach alpha of .89 [26] .

\section{Procedure}

Children in the sibling group were recruited by reputational case selection through referral by school psychologists, speech therapists and psychologists in multidisciplinary rehabilitation and special education. All parents receiving a letter provided permission in the clinical group. No parents refused permission. All older brothers or sisters (siblings) were tested individually at their homes, to verify the clinical diagnosis.

Control children (or children without family member with MLD) were recruited through letters to parents distributed in mainstream schools. Four schools accepted to participate to this study. No parents refused permission. All children were Dutch speaking at home and had no history of learning, developmental or psychiatric problems. Most parents had working and middle-class-socio-economic backgrounds.

The assessments were administered individually by trained personnel and carried out either at the school where the control children were examined, or at their homes in cases of the siblings.

\section{RESULTS}

\section{Numbersense in Kindergarten (T1)}

The Analysis Of Variance (ANOVA) with the Percentages of Absolute Error on the 0-100 number line in kindergarten as dependent variables and the group (sibling, no sibling) as independent variable revealed significant differences for the total accuracy on this task $F(1,53)=8.95 ; p=.004 ; \eta_{\mathrm{p}}{ }^{2}=.11$. In addition, the Multivariate Analysis of Variance (MANOVA) revealed differences $(F(3,51)=4.50, p=$ $.007 ; \eta_{\mathrm{p}}^{2}=.21$ ). between siblings and peers without family member with MLD on the estimation with Arabic numbers $(p=.002, \eta 2=.17)$, number words $(p=.003$, $\eta 2=.15)$ and dots; $(p=.037, \eta 2=.08)$. For $M$ and $S D$ see Table 1.

The logarithmic representation was the best fit for siblings $\left(\mathrm{R}^{2}=.717, p=.002\right)$ and non-siblings $\left(\mathrm{R}^{2}=.968, p\right.$ $<.001$ ) in kindergarten.

In addition, the MANOVA with procedural counting, conceptual counting and logical thinking as dependent variables, group (sibling, no sibling) as independent variable was significant $(F(3,50)=15.492 ; p<.001$; $\left.\eta_{\mathrm{p}}{ }^{2}=.48\right)$. Siblings differed from non-siblings on procedural counting $\left(p<.001, \eta_{\mathrm{p}}^{2}=.44\right)$, conceptual counting $\left(p<.001, \eta_{p}^{2}=.24\right)$ and logical thinking $\left(p<.001, \eta_{p}^{2}=.26\right)$. For $M$ and $S D$ see Table 1 .

\section{Numbersense in Grade 1 (T2)}

The ANOVA with the Percentages of Absolute Error on the 0-100 number line estimation in grade as

Table 1: Kindergarten (T1) Numeracy in Children with and Without Family Member with MLD

\begin{tabular}{|c|c|c|c|}
\hline & $\begin{array}{l}\text { Siblings } \\
M \text { (SD) }\end{array}$ & $\begin{array}{l}\text { No siblings } \\
M(\mathrm{SD})\end{array}$ & $F(1,53)$ \\
\hline $\begin{array}{c}\text { PAE NLE total test } \\
(\min 9.98-\max 47.16)\end{array}$ & $30.87(12.47)$ & $21.44(9.32)$ & $8.95^{*}$ \\
\hline $\begin{array}{c}\text { PAE NLE dots } \\
(\min 8.72-\max 48.16)\end{array}$ & $29.14(12.90)$ & $22.41(9.11)$ & $4.57^{*}$ \\
\hline $\begin{array}{l}\text { PAE NLE number words } \\
(\min 7.88-\max 50.64)\end{array}$ & $31.26(12.93)$ & $20.47(10.83)$ & $9.38^{* *}$ \\
\hline $\begin{array}{l}\text { PAE NLE Arabic Numbers } \\
\text { (min } 8.52-\max 45.16)\end{array}$ & $32.19(13.88)$ & $21.28(9.35)$ & $10.98^{\star *}$ \\
\hline $\begin{array}{l}\text { Procedural counting } \\
\quad(\min 0-\max 8)\end{array}$ & $3.50(1.29)$ & $6.93(1.29)$ & $41.00^{* *}$ \\
\hline $\begin{array}{l}\text { Conceptual counting } \\
\text { (min } 1-13)\end{array}$ & $7.86(2.89)$ & $11.10(2.46)$ & $16.52^{\star *}$ \\
\hline $\begin{array}{l}\text { Logical thinking } \\
\quad(\min 0-12)\end{array}$ & $2.14(1.03)$ & $6.05(3.34)$ & $18.39^{* *}$ \\
\hline
\end{tabular}

Note. $\mathrm{MLD}=$ Mathematical Learning Disability, PAE = Percentage Absolute Error, NLE =Number Line Estimation, ${ }^{* \star} \mathrm{p} \leq .01,{ }^{*} \mathrm{p} \leq .05$. 
Table 2: Numeracy in Children with/Without Family Member with MLD in Grade 1 (T2)

\begin{tabular}{|c|c|c|c|}
\hline & $\begin{array}{l}\text { Siblings } \\
M \text { (SD) }\end{array}$ & $\begin{array}{l}\text { No siblings } \\
M \text { (SD) }\end{array}$ & $F(1,53)$ \\
\hline $\begin{array}{c}\text { PAE NLE total test } \\
(\min 4.93-\max 45.11)\end{array}$ & $19.47(8.42)$ & $14.49(7.35)$ & $4.46^{\star}$ \\
\hline $\begin{array}{c}\text { PAE NLE dots } \\
(\min 3.68-\max 61.48)\end{array}$ & $17.90(13.56)$ & $15.70(8.09)$ & 0.53 \\
\hline $\begin{array}{l}\text { PAE NLE number words } \\
\text { (min } 4.08-\max 43.00)\end{array}$ & $19.45(5.45)$ & $13.86(7.94)$ & $5.96^{\star}$ \\
\hline $\begin{array}{l}\text { PAE NLE Arabic Numbers } \\
\text { (min } 3.72-\max 41.92)\end{array}$ & $21.07(7.88)$ & $13.87(6.95)$ & $10.46^{*}$ \\
\hline $\begin{array}{l}\text { Number knowledge } \\
(\min 7-\max 30)\end{array}$ & $18.71(6.41)$ & $21.80(5.78)$ & 2.82 \\
\hline $\begin{array}{l}\text { Procedural calculation } \\
\text { (min } 6-29)\end{array}$ & $15.21(6.05)$ & $20.93(5.96)$ & $9.51^{*}$ \\
\hline $\begin{array}{l}\text { Fact retrieval } \\
(\min 2-38)\end{array}$ & $13.21(5.89)$ & $23.93(5.68)$ & $6.03^{*}$ \\
\hline
\end{tabular}

Note. $\mathrm{MLD}=$ Mathematical Learning Disability, PAE $=$ Percentage Absolute Error, NLE $=$ Number Line Estimation, ${ }^{*} p \leq .05$.

dependent variables and the group (sibling, no sibling) as independent variable revealed significant differences for the total accuracy (PAE) on the number line estimation task $\left.F(1,53)=4.46, p=.040 ; \eta_{p}^{2}=.08\right)$. In addition the MANOVA revealed differences $(F(3,51)$ $\left.=7.50, p<.001, \eta_{p}^{2}=.31\right)$ between siblings and peers without family member with MLD on Arabic numbers ( $p$ $\left.=.002, \eta_{\mathrm{p}}^{2}=.16\right)$, number words $\left(p=.018, \eta_{\mathrm{p}}^{2}=.10\right)$ but no longer on dots $\left(p=.468, \eta_{p}^{2}=.01\right)$. For $M$ and $S D$ see Table 2.

The logarithmic representation was still the best fit for siblings $\left(\mathrm{R}^{2}=.730, \quad p<.001\right)$ and non-siblings $\left(R^{2}=.982, p<.001\right)$ in grade 1 (see Table 3$)$.
In addition, the MANOVA with number knowledge and procedural calculation (assessed with KRT-R) as dependent variables, group (sibling, no sibling) as independent variable was significant $(F(2,52)=5.80$; $\left.p=.005 ; \eta_{p}^{2}=.18\right)$. Siblings differed significantly from non-siblings on procedural calculation $\left(p=.003, \eta_{\mathrm{p}}^{2}\right.$ $=.15)$, with a trend for mental arithmetic $\left(p=.099, \eta_{\mathrm{p}}{ }^{2}\right.$ $=.05)$. Finally, siblings differed from non-siblings on fact retrieval $(t(53)=6.031 ; p<.001)$ in grade 1 . For $M$ and $S D$ see Table 2.

\section{Numbersense and Timed and Untimed Arithmetic}

NLE in kindergarten (T1) predicted $37,2 \%$ of the variance of untimed procedural calculation skills

Table 3: Linear $R^{2}$ and Logarithmic $R^{2}$ Representation in Grade 1 (T2) 0-100 Number Line

\begin{tabular}{|c|c|c|c|c|c|c|}
\hline & $R^{2}{ }_{\text {lin }}$ & $p$ & $R^{2} \log$ & $p$ & T-test & $p$ \\
\hline \multicolumn{7}{|l|}{ Total test NLE } \\
\hline Control & .877 & $<.001$ & $.982^{*}$ & $<.001$ & $t(9)=3.794$ & $.004^{*}$ \\
\hline Siblings & .730 & .002 & $.931^{* *}$ & $<.001$ & $t(9)=3.781$ & $.004^{*}$ \\
\hline \multicolumn{7}{|l|}{ Arabic numbers } \\
\hline Control & .885 & $<.001$ & $.969^{*}$ & $<.001$ & $t(9)=2.189$ & .056 \\
\hline Siblings & .696 & .003 & $.919^{* *}$ & $<.001$ & $t(9)=3.765$ & $.004^{*}$ \\
\hline \multicolumn{7}{|l|}{ Number words } \\
\hline Control & .936 & $<.001$ & $.983^{*}$ & $<.001$ & $t(9)=2.738$ & $.023^{*}$ \\
\hline Siblings & .767 & .001 & $.954^{* *}$ & $<.001$ & $t(9)=3.833$ & $.004^{*}$ \\
\hline \multicolumn{7}{|l|}{ Dots } \\
\hline Control & .912 & $<.001$ & $.988^{*}$ & $<.001$ & $t(9)=3.233$ & $.010^{*}$ \\
\hline Siblings & .748 & .001 & $.830^{* *}$ & $<.001$ & $t(9)=0.946$ & .369 \\
\hline
\end{tabular}

${ }^{*} \mathrm{p} \leq .05-{ }^{* *} \mathrm{p} \leq .01$. 
Table 4: Early Numercy Skills in Kindergarten (T1) and Grade 1 (T2)

\begin{tabular}{|c|c|c|c|}
\hline & $\begin{array}{c}\text { Clinical sibling } \\
\boldsymbol{M ( S D )}\end{array}$ & $\begin{array}{c}\text { Non-clinical sibling } \\
\boldsymbol{M}(\boldsymbol{S D})\end{array}$ & $\begin{array}{c}1.24 \\
0.21\end{array}$ \\
\hline \hline T1 Procedural counting & $3.00(2.52)$ & $9.00(3.46)$ & 0.72 \\
\hline T1 Conceptual counting & $8.14(2.61)$ & $2.50(0.58)$ & 3.34 \\
\hline T1 Logical thinking & $2.00(1.29)$ & $21.74(5.07)$ & $5.47^{*}$ \\
\hline T1 PAE Total NLE & $30.50(8.64)$ & $19.74(4.50)$ & 1.07 \\
\hline T1 Arabic numbers & $33.08(10.68)$ & $23.97(6.26)$ & 1.72 \\
\hline T1 Number word & $29.73(9.93)$ & $21.53(10.91)$ & 4.08 \\
\hline T1 Dots & $28.67(7.34)$ & $14.753(3.22)$ & $7.64^{*}$ \\
\hline T2 PAE Total NLE & $23.015(9.54)$ & $15.60(1.99)$ & $1.84^{*}$ \\
\hline T2 Arabic numbers & $25.17(8.23)$ & $15.64(3.17)$ & 1.40 \\
\hline T2 Number word & $22.31(5.12)$ & $13.02(5.66)$ & \\
\hline T2 Dots & $21.56(16.82)$ & & \\
\hline
\end{tabular}

$\mathrm{PAE}=$ Percentage Absolute Error, NLE =Number Line Estimation, T1=kindergarten, T2=grade 1, ${ }^{*} p \leq .05$.

$(F(1,50)=29.561 ; p<.001)$ in grade $1(T 2)$. In addition, the variance was predicted for $12.7 \%$ by counting knowledge in preschool $(F(2,49)=4.699, p=.014)$, with procedural counting knowledge as significant predictor .$(p=.042)$.

NLE in kindergarten (T1) did not significantly predict the variance in timed fact retrieval skills in grade 1 $\left(F(1,50)=0.55, \quad p=.463, \quad R^{2}=.011\right)$. However, the variance was predicted for $32.4 .7 \%$ by counting knowledge in preschool $(F(2,49)=13.23, p<.001)$, with especially procedural counting knowledge $(p<.001)$ as important predictor.

\section{Clinical Versus Non-Clinical Siblings in Kindergarten (T1) and Grade 1 (T2)}

In this sample, 8 out of 14 siblings (57\%) had clinical scores ( $\leq$ percentile 10 on KRT-R or TTR) in grade 1 pointing to MLD. The data for grade 1 were not available for one sibling. Siblings with a clinical score (or MLD) were compared with non-clinical siblings.

There was a trend of difference between both groups (clinical and non-clinical siblings) on the total score of the $0-100$ NLE task in kindergarten $(F(1,9)=$ $\left.3.34, \mathrm{p}=.101 ; \eta_{\mathrm{p}}^{2}=.27\right)$ and in grade $1 \mathrm{~F}(1,12)=$ 4.078, $p=.066 ; \eta_{p}^{2}=.25$ ). Clinical and non-clinical siblings differed significantly on the NLE task with Arabic numbers in kindergarten $(F(1,9)=5.47, p=$ $\left..044 ; \eta_{p}^{2}=.38\right)$ and in grade $1 F(1,12)=4.078, p=$ $\left..066 ; \eta_{\mathrm{p}}^{2}=.25\right)$ and on the NLE task with number words in grade $1\left(F(1,12)=7.838, p=.016, \eta_{p}{ }^{2}=.39\right)$.

However, clinical siblings did not differ significantly from non clinical siblings on procedural and conceptual counting knowledge $\left(F(2,8)=0.51, p=.596, \eta_{p}^{2}=.12\right)$ or on logical thinking $(t(9)=0.722, p=.489)$ in kindergarten, see Table 4.

\section{DISCUSSION}

The aim of this study was to tapp the contribution of counting,, logical thinking and number sense in the diagnosis of MLD.

The study replicated previous research on the relationship between counting $[3,5,8]$, logical thinking [5-7] and number sense $[9,10,11,17,18]$ and arithmetic. Siblings of children with MLD had less developed number sense based on their NLE accuracy in kindergarten and in grade 1 compared to age matched peers without family members with MLD. However both groups of children did not differ on linearity of the distribution, having a logarithmic representation of numbers in kindergarten and grade 1 . In addition, the siblings had significant less developed procedural and conceptual counting knowledge and logical thinking skills.in kindergarten compared to peers without family member with MLD.

Moreover, in line with previous research [2] $57 \%$ of the siblings developed MLD themselves. Clinical siblings (developing MLD) made more errors on the NLE task in kindergarten and in grade 1 compared to siblings without clinical scores (not developing MLD). Both groups especially differed on the format with Arabic numbers (in kindergarten and grade 1) and number words (in grade 1), pointing to the fact that especially a number line estimation tasks with symbolic stimuli can be used as screener for MLD. These results 
are in line with previous research findings of children with MLD having difficulties in accessing number magnitude from symbols rather than in processing numerosity per se [27]. In addition, although siblings differed from non-siblings on counting knowledge, clinical siblings (developing MLD) did not significantly differ from non-clinical siblings (not at risk) on counting knowledge in kindergarten. So if the aim is to screen if siblings are at-risk for MLD counting knowledge might not be sensitive enough to differentiate at risk from notat risk siblings.

In addition, our findings revealed that arithmetic might not be a homogeneous ability, since number sense in kindergarten predicted one third of the variance in procedural calculation skills but non of the variance in fact retrieval skills in grade 1 . However procedural counting knowledge in kindergarten predicted one third of the variance in fact retrieval skills and one eight of the variance in procedural calculation skills in grade 1 .

These results should be interpreted with care, since there are some limitations to the present study. First, only 15 siblings of children with MLD and 8 siblings developing MLD were included. Obviously sample size is not a problem for significant (M)ANOVA's or regressions. However, when analyses have insufficient power and were not significant, a risk of type 2- or $\beta$ mistakes (concluding from the cohort that there were no differences although in reality there were differences in the population) can not be excluded. Additional research with larger groups of siblings is indicated. Moreover MLD might have many predictive components and not be a homogeneous disability [28].

Nevertheless, we confirmed the familial aggregation of MLD and revealed that number sense assessed with a symbolic number line estimation task on a $0-100$ scale in kindergarten can be useful as screener in the diagnosis of MLD at an early age.

\section{REFERENCES}

[1] Barbaresi WJ, Katusic SK, Colligan RC, et al. Learning disorder: Incidence in a population-based birth cohort (197682, Rochester, Minn). Ambulatory Pediatrics 2005; 5(5): 28189.

http://dx.doi.org/10.1367/A04-209R.1

[2] Shalev RS, Manor O, Kerem B, Ayali M, Navah B, Friedlander Y, Gross-Tsur V. Developmental dyscalculia is a familial learning dysability. J Learn Disabilit 2001; 39: 59-65. http://dx.doi.org/10.1177/002221940103400105

[3] Geary DC, Hoard MK, Byrd-Craven J, Nugent L, Numtee C. Cognitive mechanisms underlying achievement deficits in children with mathematical learning disability. Child Develop 2007; 78: 1343-59.

http://dx.doi.org/10.1111/j.1467-8624.2007.01069.x
[4]

Butterworth B. The mathematical brain. London: MacMillan; 1999.

[5] Stock P, Desoete A, Roeyers H. Detecting children with arithmetic disabilities from kindergarten: Evidence from a three year longitudinal study on the role of preparatory arithmetic abilities. J Learn Disabilit 2010; 43: 250-68. http://dx.doi.org/10.1177/0022219409345011

[6] Dowker AD. Individual differences in arithmetic. Implications for psychology, neuroscience and education. New York: Psychology Press 2005. http://dx.doi.org/10.4324/9780203324899

[7] Nunes T, Bryant P, Evans D, Bell D, Gardner A, Gardner A Carraher J. The contribution of logical reasoning to the learning of mathematics in primary school. $\mathrm{Br} \mathrm{J}$ Develop Psychol 2006; 00: 1-21.

[8] Desoete A, Stock P, Schepens A, Baeyens D, Roeyers H. Classification, seriation, and counting in Grades 1,2 , and 3 as two year longitudinal predictors for low achieving in numerical facility and arithmetical achievement. $J$ Psychoeducat Assessm 2009; 27: 252-64. http://dx.doi.org/10.1177/0734282908330588

[9] Dehaene S. Précis of the number sense. Mind Language 2001; 16: 16-36. http://dx.doi.org/10.1111/1468-0017.00154

[10] Landerl K, Bevan A, Butterworth B. Developmental dyscalculia and basic numerical capacities: a study of 8-9 year old students. Cognition 2004; 93: 99-125. http://dx.doi.org/10.1016/j.cognition.2003.11.004

[11] Piazza M, Facoetti A, Trussardi AN, Berteletti I, Conte S, Lucangeli D, Zorzi M. Developmental trajectory of number acuity reveals a severe impairment in developmental dyscalculia. Cognition 2010; 116: 33-41. http://dx.doi.org/10.1016/j.cognition.2010.03.012

[12] Mussolin C, Mejias S, Noël MP. Symbolic and nonsymbolic number comparison in children with and without dyscalculia. Cognition 2010; 115: 10-25. http://dx.doi.org/10.1016/j.cognition.2009.10.006

[13] Molko N, Cachia A, Riviere D, Mangin, JF, Bruandet M, Le Bihan D, Cohen L, Dehaene S. Functional and structural alterations of the intraparietal sulcus in developmental dyscalculia of genetic origin. Neuron 2003; 40: 847-58. http://dx.doi.org/10.1016/S0896-6273(03)00670-6

[14] Price GR, Holloway I, Rasanen P, Vesterinen M, Ansari D. Impaired parietal magnitude processing in developmental dyscalculia. Curr Biol 2007; 17: R1042-R1043. http://dx.doi.org/10.1016/j.cub.2007.10.013

[15] Rotzer S, Kucian K, Martin E, Von Aster M, Klever P, Loenneker T. Optimized voxel-based morphometry in children with developmental dyscalculia. Neurolmage 2008; 39: 417-22.

http://dx.doi.org/10.1016/j.neuroimage.2007.08.045

[16] Rubinsten O, Henik A. Automatic activation of internal magnitudes: A study of developmental dyscalculia. Neuropsychology 2005; 19: 641-48. http://dx.doi.org/10.1037/0894-4105.19.5.641

[17] Bertelli I, Lucangeli D, Piazza M, Dehaene S, Zorzi M. Numerical estimation in preschoolers. Develop Psychol 2010; 46: 545-51. http://dx.doi.org/10.1037/a0017887

[18] Booth JL, Siegler RS. Numerical magnitude representations in fluence arithmetic learning. Child Develop 2008; 79: 101631

http://dx.doi.org/10.1111/j.1467-8624.2008.01173.x

[19] Dehaene S. Varieties of numerical abilities. Cognition 1992; 44(1-2): 1-42. http://dx.doi.org/10.1016/0010-0277(92)90049-N

[20] Desoete A, Praet M, Titeca D, Ceulemans A. Cognitive phenotype of mathematical learning disabilities: What can we learn from siblings? Res Develop Disabilit 2013; 34: 404-12. http://dx.doi.org/10.1016/j.ridd.2012.08.022 
[21] Wechsler D. WPPSI-III-NL Administration and scoring manual. TX: The Psychological Corporation 2002.

[22] Dehaene S, Izard V, Piazza M. Control over non-numerical parameters in numerosity experiments. Unpublished manuscript 2005 (available at www.unicog.org). Retrieved from http://www.unicog.org/docs/DocumentationDots Generation.doc.

[23] Siegler RS, Booth JL. Development of numerical estimation in young children. Child Develop 2004; 75: 428-44. http://dx.doi.org/10.1111/j.1467-8624.2004.00684.x

[24] Grégoire J, Noel M, Van Nieuwenhoven C. TEDI-MATH. TEMA: Brussel/ Harcourt: Antwerpen 2004.

[25] Baudonck M, Debusschere A, Dewulf B, Samyn F, Vercaemst V, Desoete A. De Kortrijkse Rekentest Revision
KRT-R. [The Kortrijk Arithmetic Test Revision KRT-R]. Kortrijk, Belgium: CAR Overleie 2006

[26] De Vos T. Tempo-Test Rekenen [Arithmetic number fact test].Nijmegen: Berkhout 1992.

[27] Noel MP, Rousselle L. Developmental changes in the profiles of dyscalculia: an explanation based on a double exact-andapproximate number representation model. Frontiers Neurosci 2011; 5(165): 1-4.

[28] Pieters S, Roeyers H, Rosseel Y, Van Waelvelde H, Desoete A. Identifying subtypes among children with developmental coordination disorder and mathematical learning disabilities, using model-based clustering. J Learn Disabilit 2013; in press.

http://dx.doi.org/10.1177/0022219413491288

Received on 07-07-2013

DOI: http://dx.doi.org/10.6000/2292-2598.2013.01.01.8

\section{(C) 2013 Praet et al.; Licensee Lifescience Global.}

This is an open access article licensed under the terms of the Creative Commons Attribution Non-Commercial License (http://creativecommons.org/licenses/by-nc/3.0/) which permits unrestricted, non-commercial use, distribution and reproduction in any medium, provided the work is properly cited 